\title{
Tensile Properties of Diffusion Bonds between TiAl Intermetallic Compound and Titanium Alloy
}

\author{
Satoru Kanai*1, Sachio Seto and Hiroyuki Sugiura*2 \\ School of Engineering, Tokai University, Hiratsuka 259-1292, Japan
}

To investigate the feasibility of joining the TiAl intermetallic compound to titanium alloys, the diffusion bonding of TiAl to Ti-17 alloys (Ti-Al-Cr-Mo-Sn-Zr, near $\beta$-phase alloy) was performed, and the effects of joining parameters on the joint strength and the diffusion phase at the bonding interface were examined.

The major results are as follows:

(1) For diffusion bonding of TiAl to Ti-17, joints which fractured at the TiAl base metal on the tensile test were obtained in case where the thickness of the diffusion phase at the bonding interface exceeded $10 \mu \mathrm{m}$.

(2) The observation of the diffusion phase revealed that a solid solution of TiAl matrix containing the alloying elements of Ti-17 such as $\mathrm{Cr}, \mathrm{Mo}, \mathrm{Zr}$ and $\mathrm{Sn}$, and a small amount of $\mathrm{Ti}_{3} \mathrm{Al}$ particles were formed, while no lamellar $\mathrm{Ti}_{3} \mathrm{Al}$ detrimental to the joint strength was detected. This result can be interpreted by taking into account the effects of $\mathrm{Cr}$ and Mo on the Ti-Al phase diagram.

(3) The bonding temperature to give the maximum tensile strength of the TiAl to Ti-17 joint was found to be higher than those of TiAl to pure titanium joint and TiAl to Ti-6Al-4V alloy joint.

(Received May 26, 2005; Accepted September 15, 2005; Published November 15, 2005)

Keywords: TiAl, titanium-17, diffusion bonding, $T i_{3} A l$, tensile strength, diffusion coefficient, activation energy

\section{Introduction}

Attention has been paid to TiAl intermetallic compound (TiAl, hereinafter) since it can be used as aerospace materials etc., ${ }^{1-6)}$ especially at high temperatures. The specific gravity of TiAl (ca. 3.8) is about the half of the Ni based super alloys, and its specific strength is almost the same as or even larger than that of the Ni alloys. However, TiAl has poor workability as intermetallic compounds does in general, which leads to the difficulty in forming a complicated configuration. Accordingly, it can be one of the major impacts to expand the usage if the bonding technology of TiAl to other metals and alloys is established more thoroughly.

Efforts have been made by the authors ${ }^{7)}$ from a practical point of view on the diffusion bonding of TiAl to Ti alloys, where the bonding strength and related factors for the combination of $\mathrm{TiAl}$ to pure $\mathrm{Ti}$ (the $\alpha$-type) (TiAl/Ti, hereinafter) and TiAl to Ti-6Al-4V alloy (the $\alpha+\beta$ type) (TiAl/Ti-6Al-4V, hereinafter) were investigated, and it was found that lamellar $\mathrm{Ti}_{3} \mathrm{Al}$ was formed at the bonding interface for the both types of bonding combinations, and the joint strength was significantly reduced by its formation.

One of the joint microstructures that ensure the joint strength not less than that of the base metal might be a firm solid solution strengthening phase at the joint interface.

On the other hand, undesirable joint is broken up at the interface because of the formation of brittle microstructure. Diffusion bonding of the combination of $\mathrm{TiAl}$ and $\mathrm{Ti}$ or $\mathrm{Ti}-$ $6 \mathrm{Al}-4 \mathrm{~V}$ does not yield a remarkable joint strength as the diffusion of $\mathrm{Ti}$ and $\mathrm{Al}$ causes the formation of brittle $\mathrm{Ti}_{3} \mathrm{Al}$. Therefore, the joint strength can be improved by suppressing the formation of lamellar $\mathrm{Ti}_{3} \mathrm{Al}$ structure.

It may be one of the most ordinary ways to use an intermediate layer which can form solid solution with TiAl

\footnotetext{
${ }^{* 1}$ Graduate Student, Tokai University

${ }^{* 2}$ Graduate Student, Tokai University. Presently with JAMCO Co. Ltd.
}

and Ti alloys, though such a metal is not easy to find. It can be also proposed to find out an alloy, in which the alloying elements can form solid solution with the base metal and delay the diffusion of Ti atoms. As realized from Fick's first law of diffusion, the transport of mass through unit area in unit time is proportional to the concentration gradient. $^{8)}$ Based on this knowledge, it is essential to decrease the concentration gradient of $\mathrm{Ti}$ so that the formation of intermetallic compounds such as $\mathrm{Ti}_{3} \mathrm{Al}$ can be suppressed. It is also suggested that the joint strength can be increased because of the formation of solid solution with other alloying elements.

On the other hand, the increase in concentration gradient is reported to be effective to reduce the formation and the growth of intermetallic compounds from theoritical analysis. ${ }^{9)}$

Therefore, in this study, in order to investigate the effects of the concentration gradient to the formation of intermetallic compound was also examined.

In this study, the diffusion bonding of TiAl to Ti-17 alloy (near $\beta$ type; Ti: 83 mass\% $\%$ i) (TiAl/Ti-17, hereinafter) has been carried out, and the results obtained from the tensile test and microstructure observation have been compared with previous results of $\mathrm{TiAl} / \mathrm{Ti}(100 \mathrm{mass} \% \mathrm{Ti})$ or TiAl/Ti-6Al4V (90 mass\% Ti).

\section{Experimental Method}

The chemical compositions of TiAl and Ti-17 used in this study are shown in Tables 1 and 2 . The specimens were prepared as shown in Fig. 1. The surface to be bonded was finished by grinding on Emery paper of \#400 to \#2000 grades and subsequent buff-polishing. The parameters for the diffusion bonding experiments are listed in Table 3. The post bonding heat treatment (PBHT) conditions are also shown in Table 3, which were performed after the diffusion bonding done at a bonding temperature of $1223 \mathrm{~K}$ and a 
Table 1 Chemical composition of TiAl compound used.

\begin{tabular}{|c|c|c|c|c|c|c|c|}
\hline & $\mathrm{Al}$ & $\mathrm{Fe}$ & V & B & $\mathrm{O}$ & $\mathrm{N}$ & $\mathrm{Ti}$ \\
\hline mass $\%$ & 32.5 & 1.85 & 1.65 & 0.087 & 0.049 & 0.0113 & Bal. \\
\hline at $\%$ & 46.0 & 1.265 & 1.24 & 0.31 & 0.117 & 0.031 & Bal. \\
\hline
\end{tabular}

Table 2 Chemical composition of Ti-17 used (mass\%).

\begin{tabular}{|c|c|c|c|c|c|c|c|c|c|c|c|c|c|c|}
\hline & $\mathrm{Al}$ & B & $\mathrm{C}$ & $\mathrm{Cr}$ & $\mathrm{Cu}$ & $\mathrm{Fe}$ & $\mathrm{Mn}$ & Mo & $\mathrm{N}$ & $\mathrm{O}$ & Sn & Y & $\mathrm{Zr}$ & $\mathrm{Ti}$ \\
\hline Ti-17 & 5.03 & 0.001 & 0.019 & 3.82 & 0.002 & 0.072 & 0.005 & 3.83 & 0.004 & 0.10 & 1.90 & 0.001 & 1.59 & Bal. \\
\hline
\end{tabular}

Table 3 Main conditions of diffusion bonding.

\begin{tabular}{|c|c|c|c|c|c|}
\hline $\begin{array}{c}\text { Bonding } \\
\text { temperature }(\mathrm{K})\end{array}$ & $\begin{array}{c}\text { Bonding pressure } \\
(\mathrm{MPa})\end{array}$ & $\begin{array}{c}\text { Bonding time } \\
(\mathrm{ks})\end{array}$ & $\begin{array}{c}\text { PBHT } \\
\text { temperature }(\mathrm{K})\end{array}$ & $\begin{array}{c}\text { PBHT } \\
\text { time }(\mathrm{ks})\end{array}$ & $\begin{array}{c}\text { Vacuum atmosphere } \\
\qquad(\mathrm{Pa})\end{array}$ \\
\hline $973-1348$ & 4.9 & \multirow{3}{*}{3.6} & - & - & \multirow{2}{*}{$6.7 \times 10^{-3}$} \\
\hline $1123-1273$ & 9.8 & & & & \\
\hline 1223 & 4.9 & & $1223-1473$ & $1.8-14.4$ & $2.2 \times 10^{-3}$ \\
\hline
\end{tabular}

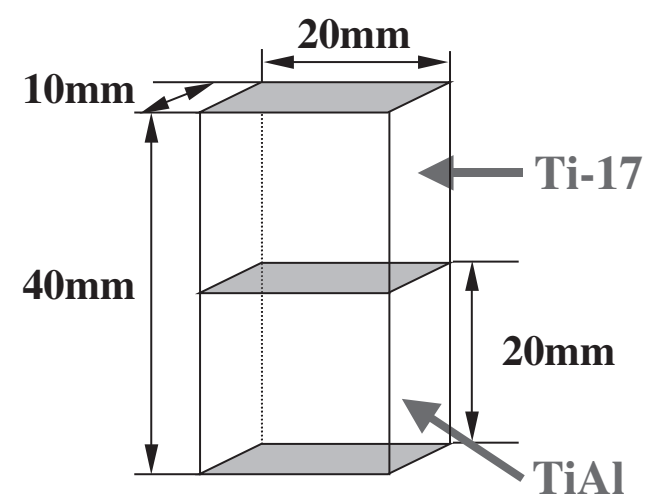

Fig. 1 Specimen configuration for diffusion bonding.

bonding pressure $4.9 \mathrm{MPa}$ for a bonding time of $3.6 \mathrm{ks}$.

Examination was also performed to obtain the relationship between the thickness of the diffusion phase and the joint strength.

The evaluation of the joint strength was made by using tensile test at a cross head speed of $1 \mathrm{~mm} / \mathrm{min}$. The microstructure of the joint was examined by observing with optical microscope, scanning electron microscope (SEM), SEM-EDX and EPMA.

\section{Experimental Results}

Figure 2 shows the tensile strength of $\mathrm{TiAl} / \mathrm{Ti}-17$ joint as a function of bonding temperature. In this experiment, the bonding time $(=3.6 \mathrm{ks})$ and the bonding pressure $(=4.9$ or $9.8 \mathrm{MPa}$ ) were kept constant. For comparison, the previous results of diffusion bonding of $\mathrm{TiAl} / \mathrm{Ti}$ and $\mathrm{TiAl} / \mathrm{Ti}-6 \mathrm{Al}-$ $4 \mathrm{~V}^{7)}$ were also shown. As can be seen, the joint strength of $\mathrm{TiAl} / \mathrm{Ti}-17$ increased with bonding temperature, and reached at almost the same level as the tensile strength of $\mathrm{TiAl}$ at $1273 \mathrm{~K}$ when the bonding pressure was $9.8 \mathrm{MPa}$ and joints bonded at the bonding temperature was fractured at the TiAl base metal.

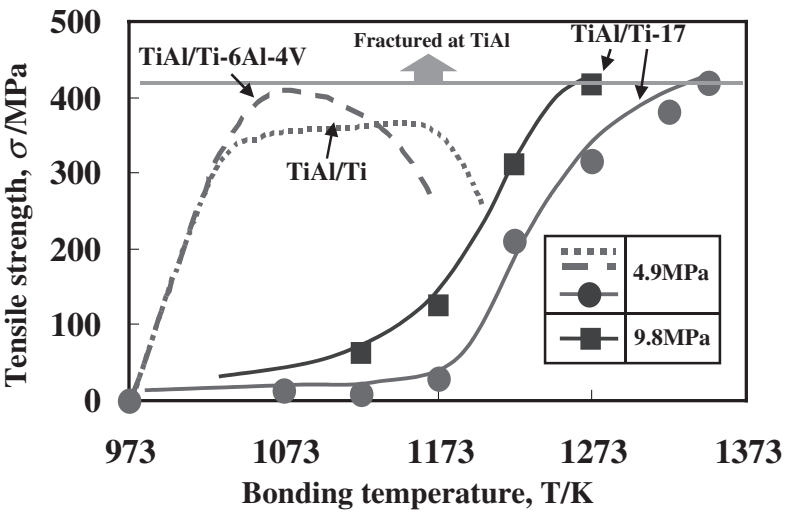

Fig. 2 Relationship between bonding temperature and tensile strength. (Bonding time: $3.6 \mathrm{ks}$ )

The temperature range that allowed the diffusion bonding of the $\mathrm{TiAl} / \mathrm{Ti}-17$ shifted to the higher side than those to obtain $\mathrm{TiAl} / \mathrm{Ti}$ and $\mathrm{TiAl} / \mathrm{Ti}-6 \mathrm{Al}-4 \mathrm{~V}$ joints. The bonding temperature to obtain the maximum tensile strength of the $\mathrm{TiAl} / \mathrm{Ti}-17$ joint at the constant bonding pressure of $4.9 \mathrm{MPa}$ and bonding time of $3.6 \mathrm{ks}$, became higher by more than $150 \mathrm{~K}$ compared with that of $\mathrm{TiAl} / \mathrm{Ti}$ joint.

The tensile strength of the joints of $\mathrm{TiAl} / \mathrm{Ti}$ and $\mathrm{TiAl} / \mathrm{Ti}-$ $6 \mathrm{Al}-4 \mathrm{~V}$ decreased with increasing bonding temperature after attaining the maximum value, and fracture occurred at the bonding interface in all the specimens. A similar phenomenon was observed in the joints of $\mathrm{TiAl} / \mathrm{Ti}-17$. However, it was difficult to perform the diffusion bonding at temperatures higher than $1473 \mathrm{~K}$ because of large deformation of $\mathrm{Ti}-17$ alloy.

In order to investigate the effects of temperature on the joint strength and the diffusion phase formed at the bonding interface, the PBHT was given to the TiAl/Ti-17 joint which was bonded at comparatively low temperatures. The results are shown in Fig. 3, where the joint tensile strength remains constant at higher temperatures than $1273 \mathrm{~K}$, and fracture occurred at the TiAl base metal. This phenomenon is 


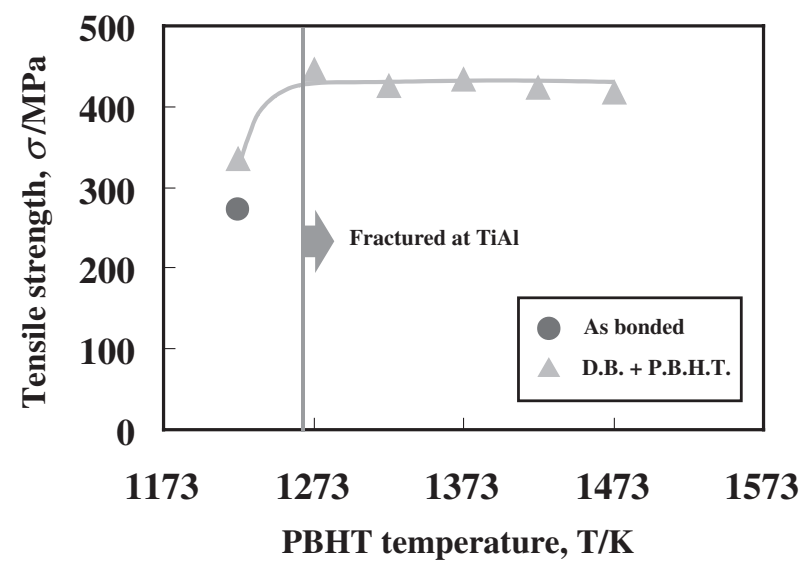

Fig. 3 Relationship between PBHT temperatures and tensile strength. $\left(\mathrm{T}_{\mathrm{B}}: 1223 \mathrm{~K}, \mathrm{P}_{\mathrm{B}}: 4.9 \mathrm{MPa}, \mathrm{t}_{\mathrm{B}}: 3.6 \mathrm{ks}\right.$, PBHT time: $\left.3.6 \mathrm{ks}\right)$

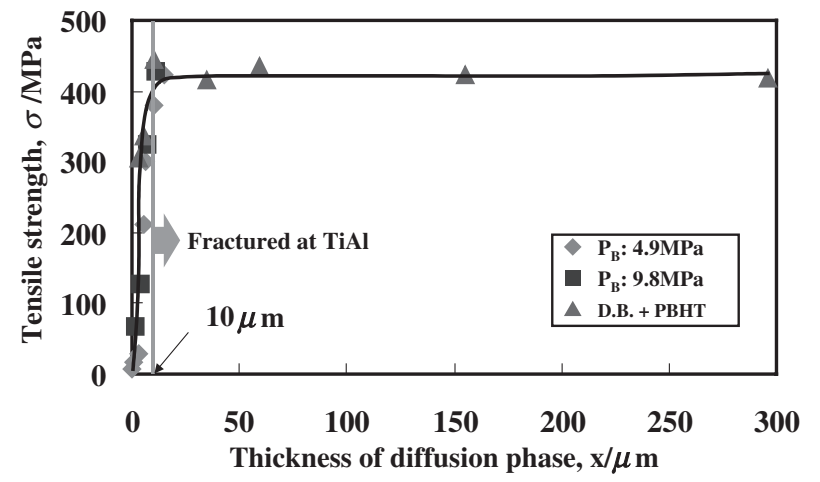

Fig. 5 Relationship between tensile strength and thickness of diffusion phase.

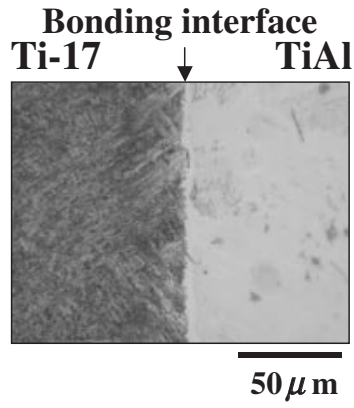

a) As bonded
Bonding interface

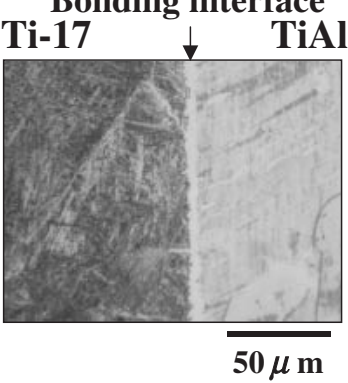

b) $1223 \mathrm{~K}$

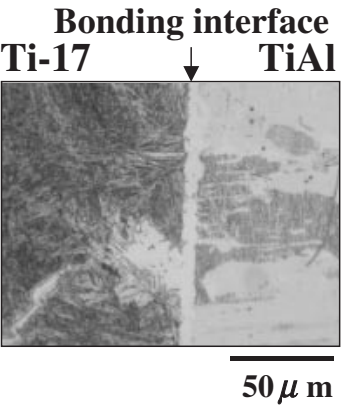

c) $1273 \mathrm{~K}$

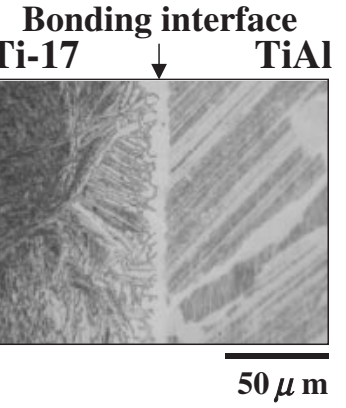

d) $1323 \mathrm{~K}$

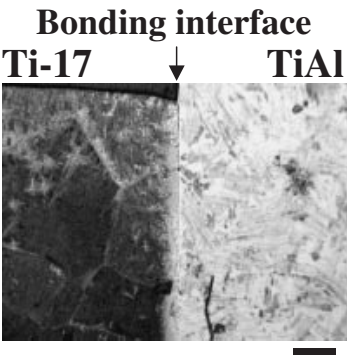

e) $1373 \mathrm{~K} 200 \mu \mathrm{m}$

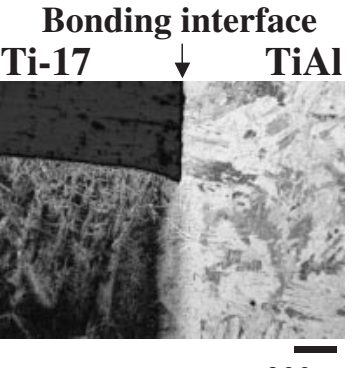

f) $1423 \mathrm{~K} 200 \mu \mathrm{m}$
Bonding interface

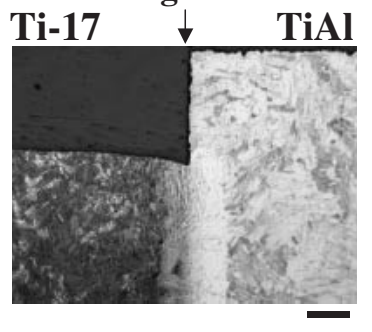

g) $1473 \mathrm{~K} 200 \mu \mathrm{m}$

Fig. 4 Microstructures of TiAl/Ti-17 joints with PBHT temperature. $\left(\mathrm{T}_{\mathrm{B}}: 1223 \mathrm{~K}, \mathrm{P}_{\mathrm{B}}: 4.9 \mathrm{MPa}, \mathrm{t}_{\mathrm{B}}: 3.6 \mathrm{ks}, \mathrm{PBHT}\right.$ time: $\left.3.6 \mathrm{ks}\right)$

different from those of $\mathrm{TiAl} / \mathrm{Ti}$ and $\mathrm{TiAl} / \mathrm{Ti}-6 \mathrm{Al}-4 \mathrm{~V}$ joints.

Figure 4 shows the microstructures of $\mathrm{TiAl} / \mathrm{Ti}-17$ joints receiving the $\mathrm{PBHT}$ under the same conditions as shown in Fig. 3. In the figure, a diffusion phase was observed at the bonding interface. The thickness of the diffusion phase increased with increasing the PBHT temperature.

Figure 5 shows the relationship between tensile strength and thickness of the diffusion phase. The joints having tensile strength not less than that of the TiAl base metal were obtained in case where the thickness of the diffusion phase exceeded $10 \mu \mathrm{m}$.

\section{Discussion}

As shown in the preceding chapter, a favorable joint, with which was fractured at the TiAl base metal on the tensile test, was obtained for the joint of TiAl/Ti-17, while no such joints were observed for $\mathrm{TiAl} / \mathrm{Ti}$ joint or $\mathrm{TiAl} / \mathrm{Ti}-6 \mathrm{Al}-4 \mathrm{~V}$.

The tensile strength of $\mathrm{TiAl} / \mathrm{Ti}$ or $\mathrm{TiAl} / \mathrm{Ti}-6 \mathrm{Al}-4 \mathrm{~V}$ decreased with increasing bonding temperature after the maximum strength and fracture occurred at the bonding interface. On the other hand, the joint tensile strength of $\mathrm{TiAl} / \mathrm{Ti}-17$, which was almost equal to that of TiAl base metal, remained the same at the higher PBHT temperature range from 1273 to $1473 \mathrm{~K}$, and fracture occurred at TiAl base metal.

The mechanism to improve tensile strength by choosing Ti-17 instead of Ti or Ti-6Al-4V as a titanium alloy and the diffusion behavior of $\mathrm{Ti}$ atoms in the $\mathrm{TiAl} / \mathrm{Ti}-17$ joint are discussed below.

4.1 Metallographic analysis on the improvement of tensile strength

As previously reported by the authors, ${ }^{7)}$ the tensile strength 


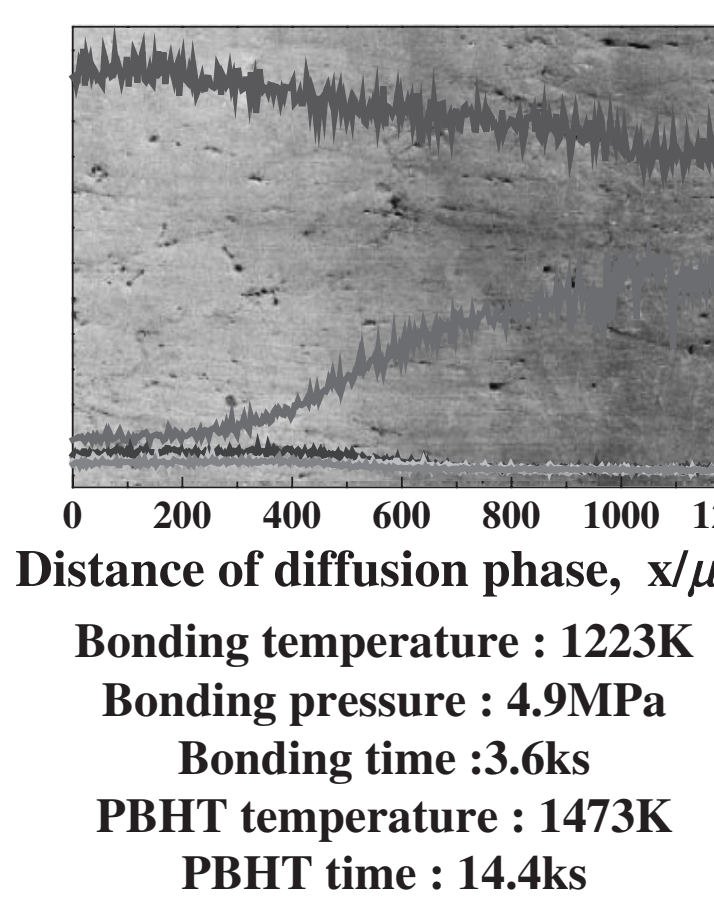

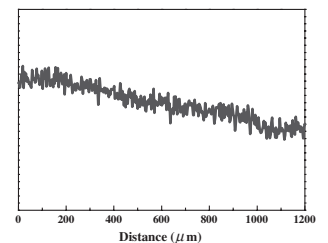

(a) $\mathrm{Ti}$

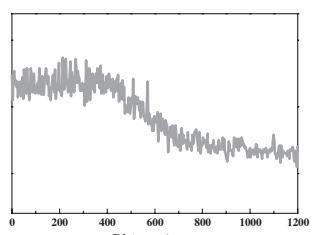

(c) $\mathbf{C r}$

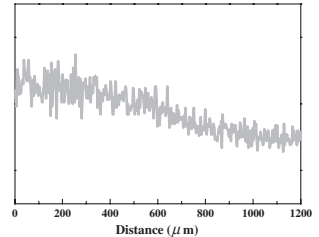

(e) $\mathbf{Z r}$

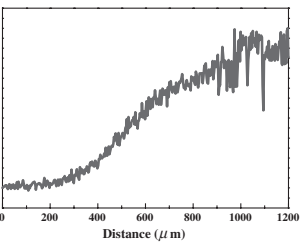

(b) Al

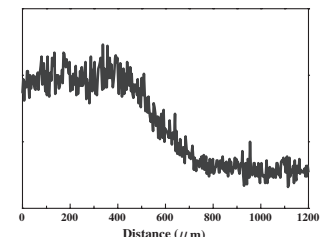

(d) Mo

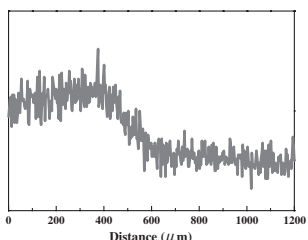

(f) $\mathrm{Sn}$

Fig. 6 Results of EPMA line analysis.

of the joints of $\mathrm{TiAl} / \mathrm{Ti}$ and $\mathrm{TiAl} / \mathrm{Ti}-6 \mathrm{Al}-4 \mathrm{~V}$ was affected strongly by the formation of lamellar $\mathrm{Ti}_{3} \mathrm{Al}$ intermetallic compound at the bonding interface. In the present experiment, the lamellar phase at the bonding interface was not observed. It is important to discuss the strengthening mechanism of the joints with this fact.

Therefore, at first, the diffusion phase at the bonding interface of TiAl/Ti-17 joint was analyzed by EPMA line analysis using the specimens in which the maximum thickness of diffusion phase was attained. Figure 6 shows one of the typical results of EPMA line analysis in the vicinity of bonding interface. In this figure, a smooth gradient of concentration is observed in each element, but a plateau of the lines which suggests the formation of compound, for example $\mathrm{Ti}_{3} \mathrm{Al}$, is not observed. Therefore, the diffusion of the atoms coexisting in $\mathrm{Ti}-17$, e.g., $\mathrm{Mo}, \mathrm{Cr}, \mathrm{Zr}$ and $\mathrm{Sn}$, can proceed by keeping a smooth concentration gradient during the diffusion process. One of the strengthening mechanism of the diffusion phase at the bonding interface of $\mathrm{TiAl} / \mathrm{Ti}-17$ joint is considered to be solid solution strengthening of the matrix alloy.

The results of SEM-EDX analysis at the reaction phase are shown in Fig. 7. From Fig. 7(a), bonding was considered to accomplish almost perfectly. From Fig. 7(b), white phase and black phase can be observed. The components of the white phase [No. 1 shown in Fig. 7(b)] are Ti, Al, Cr, Mo, etc. which are the major elements of Ti-17, while the black phase [No. 2 shown in Fig. 7(b)] is considered to be Ti-Al alloy which contains small amounts of other elements.

From the observation of above mentioned white phase, one of the strengthening mechanisms of the reaction phase at the bonding interface is considered to be solid solution strengthening of matrix. Other than these phases, white particles were observed. From the SEM-EDX analysis of the white particle
[No. 3 shown in Fig. 7(c)] observed with a higher magnification than that of Fig. 7(b), it was considered to be $\mathrm{Ti}_{3} \mathrm{Al}$. These $\mathrm{Ti}_{3} \mathrm{Al}$ particles are dispersed in the matrix phase.

Comparing with the lamellar $\mathrm{Ti}_{3} \mathrm{Al}$ layers observed in $\mathrm{TiAl} / \mathrm{Ti}$ and $\mathrm{TiAl} / \mathrm{Ti}-6 \mathrm{Al}-4 \mathrm{~V}$ joints, the dispersion of a small amount of $\mathrm{Ti}_{3} \mathrm{Al}$ particles in the matrix phase observed in TiAl/Ti-17 should be preferable from a standpoint of tensile strength properties.

Accordingly, it is concluded that strengthening factors of the diffusion phase at the interface of $\mathrm{TiAl} / \mathrm{Ti}-17$ joints are composed of two phases that are solid solution strengthening phase of the TiAl matrix and a small amount of $\mathrm{Ti}_{3} \mathrm{Al}$ particles, which in turn can improve tensile strength properties when Ti-17 is used.

Furthermore, in this case, the formation of $\mathrm{Ti}_{3} \mathrm{Al}$ phase was substantially suppressed and a small amount of $\mathrm{Ti}_{3} \mathrm{Al}$ was observed at the diffusion phase. The interpretation by the phase diagram is discussed below. Figure 8 shows the Ti-Al binary phase diagram. ${ }^{10)} \mathrm{R}$. Kainuma et al. ${ }^{11)}$ studied the phase equilibria among several phases in $\mathrm{Ti}-\mathrm{Al}$ base ternary alloys. They reported that the addition of $\mathrm{Cr}$, Mo to $\mathrm{Ti}-\mathrm{Al}$ alloy could shift the $\alpha_{2}+\gamma / \gamma$ boundary towards the TiX side at $1273 \mathrm{~K}$ in the $\mathrm{Ti}-\mathrm{Al}$ phase diagram shown in Fig. 8. Applying their finding to the present study suggests that the $\gamma$ rich phase will increase, while $\alpha_{2}$ phase decreases, during the diffusion process to $\mathrm{TiAl}$ side of $\mathrm{Cr}$ and Mo which are major elements of Ti-17. This explanation is well consistent with the experimental results mentioned above.

\subsection{Diffusion behavior of Ti atoms in TiAl on TiAl/Ti- 17 joint}

As mentioned in Fig. 2, the bonding temperature of the $\mathrm{TiAl} / \mathrm{Ti}-17$ joint at a constant bonding parameter increased by more than $150 \mathrm{~K}$ compared with that of $\mathrm{TiAl} / \mathrm{Ti}$ joint. 


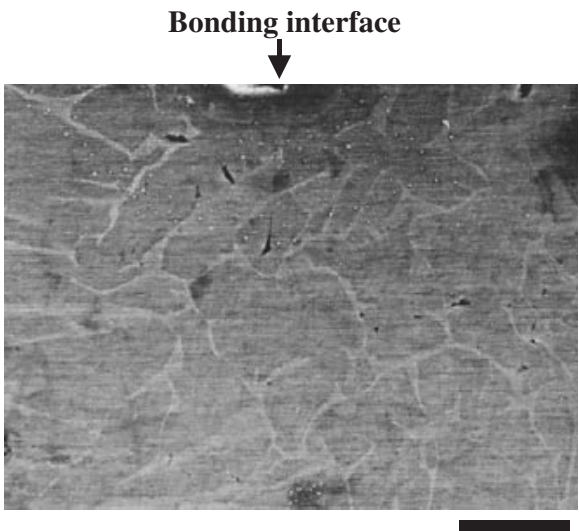

(a)

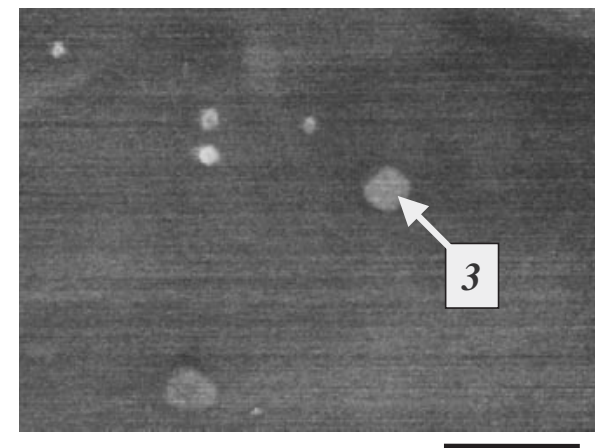

(c)

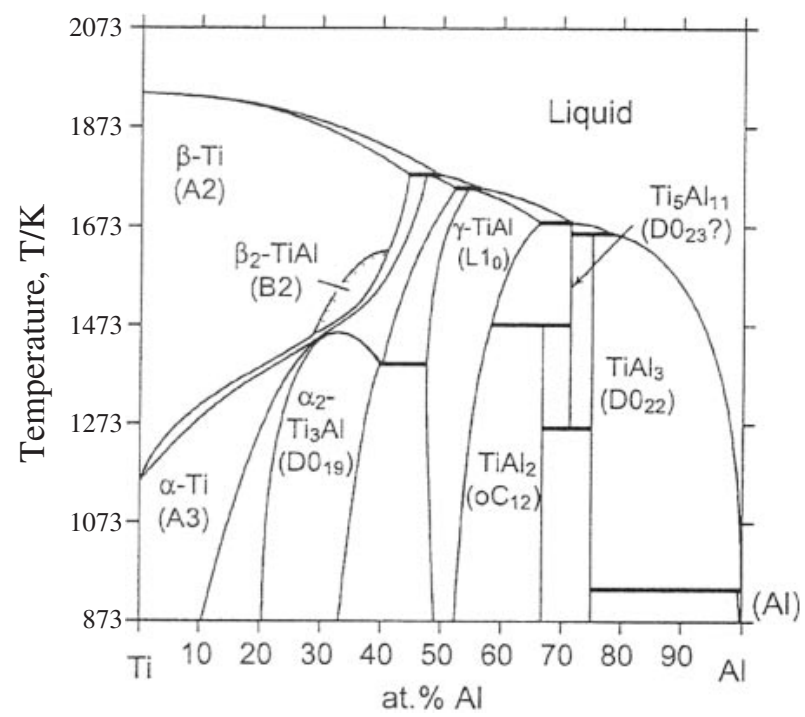

Fig. 8 Equiribrium phase diagram of Ti-Al.

From the results of diffusion bonding experiment of TiAl/ $\mathrm{Ti}-17$, it was observed that the solid solution phase and $\mathrm{Ti}_{3} \mathrm{Al}$ particles were formed and the formation of lamellar $\mathrm{Ti}_{3} \mathrm{Al}$ was suppressed. Therefore, in order to clarify the diffusion behavior of $\mathrm{Ti}$ atom on $\mathrm{TiAl} / \mathrm{Ti}-17$ joint, diffusion coefficient and activation energy were measured and discussed as below.

Although even the diffusion coefficient is not very easy to obtain, a rough estimation of the value is given by the following equation: ${ }^{12)}$

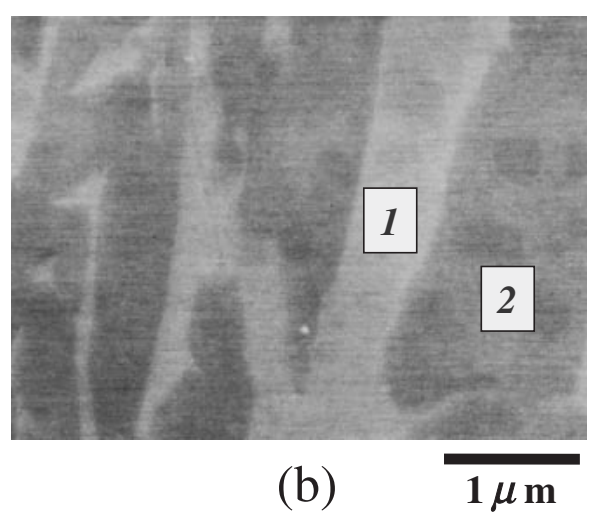

\begin{tabular}{|c|c|c|c|c|}
\hline Unit : at \% & $\mathrm{Ti}$ & $\mathrm{Al}$ & $\mathrm{Cr}$ & $\mathrm{Mo}$ \\
\hline 1 & 75.91 & 11.69 & 8.21 & 4.19 \\
\hline 2 & 75.84 & 22.79 & 0.00 & 1.37 \\
\hline 3 & 68.87 & 30.55 & 0.58 & 0.00 \\
\hline
\end{tabular}

Fig. 7 Results of SEM-EDX analysis. $\left(\mathrm{T}_{\mathrm{B}}\right.$ : $1223 \mathrm{~K}, \mathrm{P}_{\mathrm{B}}$ : $4.9 \mathrm{MPa}, \mathrm{t}_{\mathrm{B}}: 3.6 \mathrm{ks}$, PBHT temperature: $1473 \mathrm{~K}$, PBHT time: $14.4 \mathrm{ks}$ )

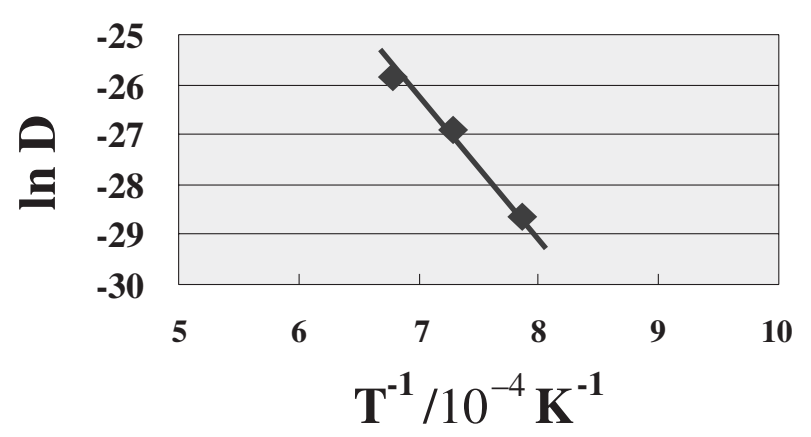

Fig. 9 Relationship between temperature and diffusion coefficient.

$$
\begin{aligned}
& X=\left(2 D_{\mathrm{t}}\right)^{1 / 2} \\
& D=D_{0} \exp (-Q / R T)
\end{aligned}
$$

where $X$ is diffusion distance, and $t$ the treatment time.

The diffusion coefficient of $\mathrm{Ti}$ atoms onto $\mathrm{TiAl}$ at the bonding interface of $\mathrm{TiAl} / \mathrm{Ti}-17$ joint was measured by the post bonding heat treatment experiment. In this case, each diffusion distance $X$ of Ti atoms was measured with EPMA line analysis curves. Therefore, the value is different from the thickness of diffusion phase. The relationship between temperature and diffusion coefficient is shown in Fig. 9. From this figure and the above Arrhenius equation, the following values were obtained:

$$
\begin{aligned}
& D_{0}=3.26 \times 10^{-4}\left(\mathrm{~m}^{2} / \mathrm{s}\right) \\
& Q=501(\mathrm{~kJ} / \mathrm{mol})
\end{aligned}
$$


where $D_{0}$ is the pre-exponential factor and $Q$ is activation energy of Ti onto TiAl of TiAl/Ti-17 joint.

As reference, the minimum values of $D_{0}$ and $Q$ reported in the tracer diffusion of $\mathrm{Ti}$ atoms in $\mathrm{TiAl} / \mathrm{Ti}^{13)}$ are as follows:

$$
\begin{aligned}
& D_{0}=7.66 \times 10^{-4}\left(\mathrm{~m}^{2} / \mathrm{s}\right) \\
& Q=311(\mathrm{~kJ} / \mathrm{mol})
\end{aligned}
$$

Comparing the present results with the literature data, the apparent diffusion coefficient of $\mathrm{Ti}$ atoms in $\mathrm{Ti}-17$ onto $\mathrm{TiAl}$ was found to be smaller than that in Ti. It is clear that diffusion of $\mathrm{Ti}$ atoms onto $\mathrm{TiAl}$ in $\mathrm{TiAl} / \mathrm{Ti}$ alloy joint was suppressed by replacing $\mathrm{Ti}$ or $\mathrm{Ti}-6 \mathrm{Al}-4 \mathrm{~V}$ to $\mathrm{Ti}-17$ as $\mathrm{Ti}$ alloy. This kind of interpretation can well correspond to the above mentioned experimental facts shown in Fig. 2.

The formation of lamellar $\mathrm{Ti}_{3} \mathrm{Al}$ will discuss below. In Fig. 2, the bonding temperature at the constant bonding parameters in tensile strength of $\mathrm{TiAl} / \mathrm{Ti}$ joints was higher by about $100 \mathrm{~K}$ than that of $\mathrm{TiAl} / \mathrm{Ti}-6 \mathrm{Al}-4 \mathrm{~V}$ joint. The larger concentration gradient for TiAl to pure Ti than that for TiAl to $\mathrm{Ti}-6 \mathrm{Al}-4 \mathrm{~V}$ which contains $6 \% \mathrm{Al}$ is considered to decrease the formation and the growth of intermetallic compounds. The fact is well coincident with the theoritical analysis on the formation of intermetallic compounds described in the introduction. ${ }^{9)}$ This discussion is only valid in case when it is assumed that the addition of $4 \% \mathrm{~V}$ does not affect the binary Ti-Al phase diagram largely.

On the other hand, the bonding temperature in the $\mathrm{TiAl} /$ $\mathrm{Ti}-17$ joints was higher above $150 \mathrm{~K}$ than that of $\mathrm{TiAl} / \mathrm{Ti}$ joints at constant bonding pressure of $4.9 \mathrm{MPa}$ and bonding time of $3.6 \mathrm{ks}$ (Fig. 2). In this case, the phase diagram of Ti17 may substantially change the original phase diagram, because of the alloying elements of $4 \% \mathrm{Cr}, 4 \% \mathrm{Mo}, 2 \% \mathrm{Sn}$ and $2 \% \mathrm{Zr}$. Therefore, the formation rate of $\mathrm{Ti}_{3} \mathrm{Al}$ compound in $\mathrm{TiAl} / \mathrm{Ti}-17$ and $\mathrm{TiAl} / \mathrm{Ti}$ cannot be discussed only from the viewpoint of the concentration gradient.

\section{Conclusion}

It is essential to improve the joint strength of diffusion bonding between TiAl intermetallic compound and titanium alloys. In this study, the diffusion bonding between TiAl and Ti-17 alloys was performed and the effects of joining factors on the joint strength and the diffusion phase at the bonding interface were examined.
The major findings are as follows:

(1) For diffusion bonding between $\mathrm{TiAl}$ and $\mathrm{Ti}-17$, a favorable joint, with which the fracture occurred at the TiAl part during the tensile test, was obtained in case where the thickness of the diffusion phase at the bonding interface exceeded $10 \mu \mathrm{m}$.

(2) As a result of the observation on the reaction phase, solid solution of TiAl matrix containing the coexisting elements of Ti-17 such as $\mathrm{Cr}, \mathrm{Mo}, \mathrm{Zr}$ and $\mathrm{Sn}$, and a small amount of $\mathrm{Ti}_{3} \mathrm{Al}$ particles were observed. However, lamellar $\mathrm{Ti}_{3} \mathrm{Al}$ was not observed. These phases are considered as one of the strengthening factors of the joints.

Furthermore, the fact that the formation of $\operatorname{TiAl}(\gamma)$ rich phase occurred more easily while the $\operatorname{Ti}_{3} \operatorname{Al}\left(\alpha_{2}\right)$ decreased, can be well interpreted by taking the increase of $\mathrm{Cr}$ and $\mathrm{Mo}$ in the $\mathrm{Ti}-\mathrm{Al}$ phase diagram into account.

(3) The bonding temperature to give the maximum tensile strength of TiAl/Ti-17 joint increased by more than $150 \mathrm{~K}$ compared with those of $\mathrm{TiAl} / \mathrm{Ti}$ and $\mathrm{TiAl} / \mathrm{Ti}-$ $6 \mathrm{Al}-4 \mathrm{~V}$ joints at the constant bonding pressure and bonding time.

The apparent diffusion coefficient of $\mathrm{Ti}$ atoms in $\mathrm{Ti}-17$ to TiAl was found to be smaller than that with pure Ti to TiAl.

\section{REFERENCES}

1) H. Hino, T. Miyashita and S. Minakata: Light Metals 43 (1993) 545555.

2) T. Noda: Titan $\mathbf{5 0}$ (2001) 17-20.

3) T. Tetsui and Y. Miura: Titan 48 (2000) 211-215.

4) S. Isobe: SOKEIZAI 30 (1989) 1-5.

5) Kawasaki Heavy Industries Ltd. Technical research center: SOKEIZAI 29 (1988) 12.

6) M. Mizuno: DENKI-SEIKO 70 (1999) 79-87.

7) S. Kanai, S. Seto and T. Wada: Q. J. J. W. S. 22 (2004) 580-586.

8) P. G. Shewmon: Diffusion in Solids, (McGraw-Hill Book Co, 1963).

9) K. Kobayashi, K. Nishimoto and K. Ikeuchi: ZAIRYOU SETSUGOU KOUGAKU NO KISO, (Sanpo pub, 2000) p. 187.

10) H. Okamoto: ASM International (2000) 46.

11) R. Kainuma, Y. Fujita, H. Mitsui, I. Ohnuma and K. Ishida: Intermetallics 8 (2000) 855-867.

12) Y. Mishima: KINZOKU ZAIRYOU GAIRON, (NIKKAN KOGYO SHIMBUN, LTD., 1978) pp. 59-60.

13) T. Ikeda, H. Kadowaki, H. Nakajima, H. Inui, M. Yamaguchi and M. Koiwa: Mater. Sci. Eng. A A312 (2001) 155-159. 